\title{
Institutional Methods for the Identification of Urban and Rural Areas-A Review for Italy
}

\author{
Valentina Cattivelli
}

\begin{abstract}
Recent economic, demographic, and spatial changes have profoundly modified urban and rural areas and generated new territories, characterized by varying degrees of urbanity. The classification methods traditionally used to identify them are based on the distinction between urban and non-urban areas and are no longer functional to describe the territorial outcomes of these transformations. New methods have therefore been formulated and implemented in recent years to replace them. EUROSTAT has developed and updated periodically its own methods, intended to methodologically support scholars to read territorial diversities and transformations. Being the basis for the production of official statistics and data comparison between regions, these methods have fully replaced all the other methods that singular statistical offices of European countries had previously developed. Several government institutions began adopting specific territorial classifications in their strategic planning documents. These methods differed from those implemented by statistical offices, providing a more accurate and detailed framework for national and regional policies. This also happened in Italy, with ISTAT (Istituto Nazionale di Statistica-National Statistical Office) and many governmental institutions (e.g., National Government Institutions, Department for Economic Development and Cohesion, Ministry for Agricultural Policies, National Rural Network), experimenting with their own urbanrural classification methods to map all or part of the Italian territory. This paper offers an overview of the methods formulated and implemented in Italy over the last 15 years by ISTAT and governmental institutions. During this time, these institutions have developed six different methods to define urban and rural territories and to delimit territories with several degrees of urbanization, such as peri-urban areas. Specifically, ISTAT uses the EUROSTAT method to produce international and national statistics. Governmental institutions adopt methods based on economic and demographic data, which identify various territorial categories in addition to urban/rural ones, in their strategic planning documents. These findings result from desk research based on an analysis of official documents and scientific papers.
\end{abstract}

Keywords Urban-rural typologies $\cdot$ Territorial mapping $\cdot$ Italy

V. Cattivelli $(\varangle)$

Institute for Regional Development—Eurac Research, viale Druso 1, Bolzano/Bozen, Italy

e-mail: valentina.cattivelli@eurac.edu; valentina.cattivelli13@gmail.com

(C) The Author(s) 2021

A. Bisello et al. (eds.), Smart and Sustainable Planning for Cities and Regions,

Green Energy and Technology, https://doi.org/10.1007/978-3-030-57764-3_13 


\section{Introduction}

Urban and rural areas have changed profoundly in recent decades and have lost their clear and defined connotations (Cattivelli 2011, 2012, 2018; Hugo 2017; Dijkstra and Poelman 2017; Arellano and Roca 2017). This has occurred due to demographic dynamics, changes in settlement intensity and economic specialization, which have followed different paths from those traditionally defined by urbanistic literature (e.g., Wandl et al. 2014; Dymitrow and Stenseke 2016).

Urban peripheries and fringes grow more rapidly than core areas since population and economic activities are reversed in such contexts (EUROSTAT 2017). Relocation of people and economic activities leads to an explosion of the cities into the countryside, with the consequent conversion of agricultural land for productive and residential purposes in nearby rural areas. This, in turn, generates a sort of territorial continuum with no precise geographical identity, giving rise to peri-urban territories that are incredibly challenging to govern. Such territories are located within the urban fringes, on the edges of the built-up areas and close to rural areas, and tend to comprise a scattered pattern of lower density settlements and production zones around the main infrastructural hubs (Donadieu 2012; Wandl and Magoni 2017). Their spread creates urban conurbations with nearby small-medium cities, while also encompassing nearby rural areas (Simon et al. 2006; Simon 2008). Here, the characteristics of urban and rural zones merge in a disorderly, unplanned way, which can sometimes give rise to land tenure-related conflicts (Dadashpoor and Somayeh 2019). Investments in transport infrastructure reduce distances among urban fringes, peri-urban areas and nearby rural areas, and increase accessibility to work opportunities and services located in core urban areas (Accetturo 2018). This in turn intensifies commuting flows and requires spatial reorganization of public spaces and services (Timberlake 2017).

Changes in rural areas, where agriculture remains the most practiced economic activity (EUROSTAT 2017), are partly dictated by variations in production specialization. Due to the relocation of many industries, however, the secondary sector is growing, which in turn also attracts many companies from the tertiary sector, particularly in rural areas closer to urban centers (Cattivelli and Iuzzolino 2014). The latter territories are very dynamic, including from a demographic perspective, and enjoy economic benefit arising from their proximity to urban areas. Conversely, remote rural areas continue to suffer from depopulation, population aging and lack of job opportunities (ESPON 2018).

Considering these transformations, traditional territorial methods based on the urban-rural dichotomy are no longer appropriate as a framework for considering. "Urban" and "rural" as well-identified territorial categories are assumed to exist only at the extreme ends of a territorial continuum (Davoudi and Stead 2002; Donadieu 2012; Mustafa et al. 2015). This continuum or peri-urban area is difficult to map due to its complexity. No classification method enables its inclusion in a well-defined category (Pagliacci 2017). 
New urban-rural typologies are required, as are more appropriate definitions of the continuum between these two territories. Firstly, these new definitions could methodologically support scholars to investigate the current territorial configurations and different characteristics of urban and rural areas more accurately. Secondly, they could serve to steer the attention of local policymakers toward the implementation of more territorial-targeted policies to promote local development. Finally, they will also be of interest to those involved in local development policies and allocation of resources at a higher territorial levels (national and European governments), as well as journalists, researchers, and citizens interested in the classification and characteristics of urban and rural areas.

In response to these needs, 80 different methods have been developed in Europe over the last 15 years, which can be clustered into three well-defined categories, based on their originator (statistical institutions, government, or scholars) (Cattivelli 2018).

The first kind of method is used for statistical purposes and specifically to prepare reports and publications, including national statistical analyses. Formulated and implemented by national statistical institutes to map the entire national territory, these methods are based on administrative boundaries and generally use few variables (ibid.).

The second group consists of territorial-targeted methods, which are adopted by state and regional institutions as territorial frameworks for formulating measures and programs (e.g., Piano di sviluppo rurale-Rural development plan). The third and final group is much more heterogeneous, encompassing all the methods developed by scholars to support policymakers and to map territorial changes with greater precision. As such, these methods employ sophisticated statistical techniques to manage many indicators, particularly social, economic, demographic, and morphological ones.

All these methods differ depending on the choice of indicators, territorial unit of analysis, statistical method, and number of classes adopted (Cattivelli 2011, 2012, 2018).

\section{Aims}

The aim of this short paper is to illustrate the main characteristics of urban-rural classification methods adopted over the last 15 years in Italy by statistical and governmental institutions. The methods developed by scholars will be the subject of a later study.

According to the OECD methodology, 24\% of the Italian territory consists of predominantly urban territories, $49.2 \%$ of intermediate territories, and $26.8 \%$ of predominantly rural ones (OECD-EUROSTAT 2011). This breakdown is the result of an intense process of urbanization (Romano et al. 2017), which has quickened considerably over the past 50 years. Even in the 1950s, buildings were distributed 
widely throughout the territory, but outside cities they were mainly used for agricultural purposes. The countryside only became urbanized later, when residential, industrial, and service buildings poured into areas apart from the most densely populated cities, in smaller urban centers or rural municipalities near larger urban areas. According to ANCI (2018), 1000 Italian municipalities (out of a total of 8000) grew by more than $160 \%$ demographically between 1971 and 2019. Their spatial distribution underlines a shift in part of the urban population: toward smaller municipalities on the one hand, and toward the countryside on the other. The countryside is becoming increasingly urbanized, thus influencing the expansion of peri-urban areas around the most important urban centers (Esposito et al. 2018; Caracciolo 2018). In contrast, population growth in urban centers during the same period was found to be stable, or even negative (ibid).

This process of urbanization and peri-urbanization has made the boundaries between urban and rural areas less defined, generating peri-urban territories. Their delimitation is an urgent prerequisite for local policies and studies. This requires new methods of urban-rural and peri-urban identification to be developed, as those currently used do not identify peri-urban areas or do not accurately describe the territorial heterogeneity because they are based on the urban-rural dichotomy. Attempts to formulate new, more precise identification methods have led to their proliferation across Europe. Several statistical and governmental institutions and scholars have developed numerous methods at municipal, regional and national levels, in addition to those applied at a European level. Italy is the European country that has developed the most urban-rural methods, together with France and Germany (Cattivelli 2018). This indicates a willingness to read and describe the territorial complexity of our country. However, it also requires reflection on existing methods and their ability to represent territorial peculiarities.

\section{Methods}

This short paper illustrates the results of a desk research analysis undertaken in 2017 and completed one year later. Adopting the categorization approach proposed by Cattivelli (2018) to group existing urban-rural classification methods depending on the subjects who developed them, the research analyzes the statistical methods introduced by statistical institutions and the territorial-targeted methods adopted by governmental institutions.

As such, it studies the official documents drawn up by statistical and government institutions to delimit urban and rural areas, as well as to identify peri-urban areas or other territories with varying degrees of urbanization. Specifically, it focuses on analyzing the documents draft by ISTAT (Istituto Italiano di Statistica-National statistical institute), with the aim of investigating which classification methods this institution adopted to identify urban and rural areas in Italy during the 20052020 period. Subsequently, the research focuses on a study of national strategic planning documents to identify the methods adopted in the context of territorial 
development policies over the last two periods (2007-2013; 2014-2020) (Piano di sviluppo Nazionale_-Plan of national development; Strategie Aree Interne-Inner areas strategy; Rete Rurale Nazionale-Rural National Network and Ministero delle politiche agricole alimentari, forestali e del turismo-Ministry of Agricultural, Food, Forestry and Tourism Policies plans).

The documents considered were requested and obtained directly from ISTAT and the Italian government offices.

Each method identified is analyzed specifically according to certain characteristics, such as the statistical units of reference and methodologies adopted, as well as the territorial typologies identified. The main results are described in the following sections, while Appendix provides a synoptic table summarizing the main features.

\section{Results}

The study identified six different methods that distinguish urban and rural areas and delimit the emerging peri-urban territories by defining various degrees of urbanization.

Section 4.1 describes the method adopted by ISTAT while Sect. 4.2 explores the methods developed by national government institutions.

\subsection{The Method Adopted by ISTAT}

ISTAT has adopted the EUROSTAT-OECD method to produce official statistics at the national level. This method was developed in 2010 (EUROSTAT 2010) but has been adapted over time as appropriate to take into account the presence of peri-urban territories and the influence exerted by larger urban centers.

Currently, it refers to grids and uses demographic data (easy to collect and updated periodically) to map all European territories. Procedurally, it implements a simple two-step approach to identifying population in urban areas based on the calculation of:

1. the population density threshold (300 inhabitants per $\mathrm{km}^{2}$ ) applied to grid cells of $1 \mathrm{~km}^{2}$.

2. the minimum size threshold (5000 inhabitants) applied to grouped grid cells above the density threshold.

The population living in rural areas is calculated by considering the population located outside urban areas, identified using the method just described. Population size is determined through the grouping of cells based on contiguity. If the central square of this grouping is above the density threshold, it will be grouped with each of the other surrounding eight cells that exceed the density threshold. This procedure is performed for all grids within NUTS 3. Threshold percentages are then applied 
at NUTS 3 level for the calculation of population density. Population thresholds are similar to those of the original OECD ${ }^{1}$ classification applied to NUTS 3 regions, with the exception of that used to distinguish predominantly urban from intermediate areas, which has been adjusted from 15 to $20 \%$. Moreover, the same three urban-rural typologies are applied: predominantly urban regions, intermediate regions (which can be proxied to peri-urban territory or the urban-rural continuum), and predominantly rural regions.

The main difference from the original OECD classification is the statistical unit of reference. Instead of using LAU 2 s, the OECD-EUROSTAT uses the population share of rural grid cells.

This method resolves two types of distortions. The first is connected to the large variation in terms of area of LAU 2 local administrative units in Europe. Some municipalities are too extended; others are too small. Moving straight from the grid to the regional level circumvents the distortion associated with the variable size of LAU 2s. The second distortion is due to the large variation in size of NUTS 3 regions, and the practice in some countries of separating a small city center from the surrounding region. This method proposes a different approach to resolve the problem of excessively small NUTS 3 regions, by combining those smaller than $500 \mathrm{~km}^{2}$ with their neighboring NUTS 3 regions.

By resolving these two distortions, this approach can be applied uniformly to all NUTS 3 regions in the EU. Figure 1 here and Table 1 in the annex illustrate the characteristics of this new method and its application to European territory. The map that emerges from Italy is of a country characterized by the presence of intermediate and mainly rural territories, where urban areas are confined to a few territories around Milan, Turin, Rome, Naples, and Palermo.

In this country, it has replaced a method that has been used for many years by ISTAT and that allowed Italian municipalities to be differentiated based on the degree of urbanization (ISTAT 2017). This previous method distinguished rural from urban municipalities based on population density. Municipalities with less than 100 inhabitants per $\mathrm{km}^{2}$ were considered rural, while those with more than 100 urban inhabitants were classified as urban (ibid.).

\footnotetext{
${ }^{1}$ This classification involves two steps:

- defining rural local administrative units level 2;

- based on the population share in rural LAU 2 s, classifying the regions.
}

It classifies LAU $2 \mathrm{~s}$ with a population density below 150 inhabitants per $\mathrm{km}^{2}$ as rural. Due to the heterogeneity of size in area of LAU 2 s, some LAU 2 s will be incorrectly classified. Subsequently, it classifies regions as predominantly urban, intermediate or predominantly rural based on the percentage of population living in local rural units. A NUTS 3 region is classified as:

- predominantly urban (PU), if the share of population living in rural LAU 2 is below 15\%;

- intermediate (IN), if the share of population living in rural LAU 2 is between 15 and 50\%;

- predominantly rural (PR), if the share of population living in rural LAU 2 is higher than $50 \%$. 


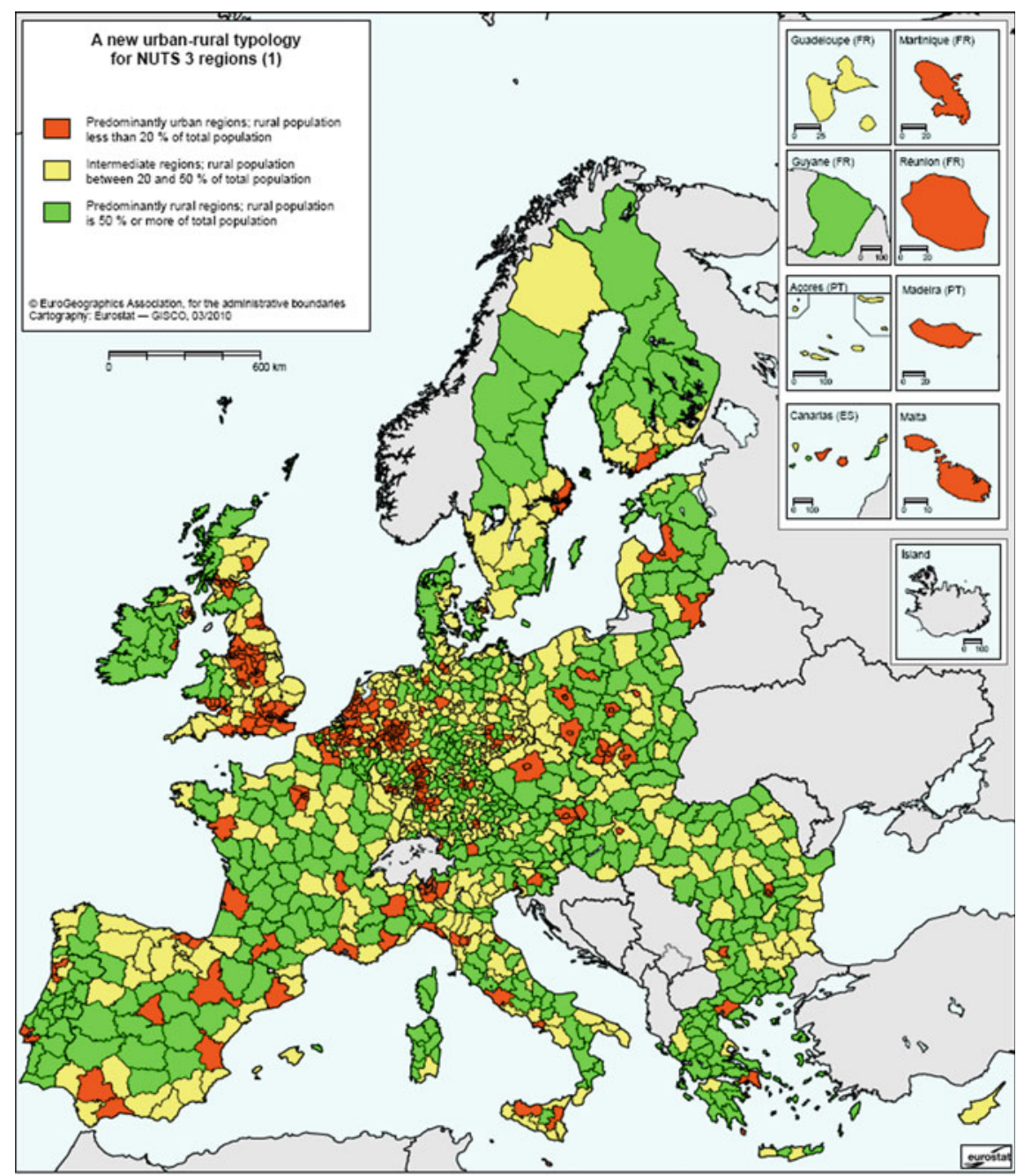

(1) This typology is based on a definition of urban and rural $1 \mathrm{~km}^{2}$ grid cells. Urben grid cells fulfil two conditions: 1) a population density of at least 300 inhabitants per $\mathrm{km}^{2}$ and 2) a minimum population of 5000 inhabitants in consiguous cells above the density threshold. The other cells are considered rural. Thresholds for the typology. $50 \%$ and $20 \%$ of the regional population in rural grid cells.

For Madeira, Açores and the French outermost regions, the population grid is not available. As a result, this typology uses the OECD classification for these regions.

Fig. 1 A map of urban-rural typologies for European NUTS 3 regions according to OECDEUROSTAT method. Source EUROSTAT (2018)

\subsection{Methods Developed by National Government Institutions}

In their National Strategic Plan for the 2007-2013 period, the Italian government adopted an urban-rural classification method like the original OECD method. It consists of four phases. The first involves the selection of all Italian municipalities 
with more than 150 inhabitants $/ \mathrm{km}^{2}$, which are considered urban poles. These municipalities represent the most important urban centers based on the concentration of non-agricultural activities and population. The second phase involves application of the OECD method to the remaining municipalities to identify those predominantly urban (population rural municipalities $<15 \%$ of total population), significantly rural (population of rural municipalities $>15 \%$ and $<50 \%$ of total population), and predominantly rural municipalities (population of rural communes $>50 \%$ of total population). In the third phase, the method rearranges these municipalities according to their altitude and the incidence of the importance of agriculture. Specifically, it differentiates municipalities within each province, by altitude zone and, for each of these three zones (plains, hills, and mountains), calculates the incidence of population municipalities classified as rural in the overall population. This is a novelty compared to the OECD method and others previously adopted. At the end of the final phase, the method identifies four different typologies of territories (urban poles, rural areas specializing in intensive agriculture, intermediate rural areas and rural areas with development problems). Figure 2 demonstrates the cartographic application of this method.

For the subsequent 2014-2020 programming period, the Italian Government refined this classification. Specifically, it has continued to consider the three different areas in terms of altitude (mountain, plain, and hill) with the four categories of territories obtainable by applying the OECD methodology. Unlike in the previous period, however, it now performs a fine-tuning process at a regional level with local administrations following the matching procedure. This process involves bilateral negotiation with local administrations to finalize and refine the territorial classifications resulting from application of the matching procedure, so that it more accurately describes the diversity of the local urban and rural areas. Figure 3 illustrates the result of applying this method, which does not produce a map not dissimilar to the previous one. Some differences do exist, however, particularly in Calabria and southern Italy, more generally.

In the same period, the Department for Economic Development and Cohesion developed the Strategy for Inner Areas, containing a series of measures for the promotion of territories defined as inner areas based on certain economic criteria. The method for identifying inner areas is based on the belief that these territories are characterized by inadequate supply of public services, but extensive availability of natural assets (water resources, forests, natural landscape, etc.) and cultural resources (craft centers, archaeological settlements, etc.). It applies a two-step approach that does not use demographic criteria.

First, it identifies single or multi-service centers as those municipalities that offer an exhaustive range of secondary schools, at least one highly specialized hospital and a "silver standard" (not small) railway station. Secondly, it defines the remaining municipalities according to their distance from these centers as:

- Belt areas - up to 20 min from the centers.

- Intermediate areas-between 20 and 40 min away.

- Remote areas-between 40 and 75 min away. 


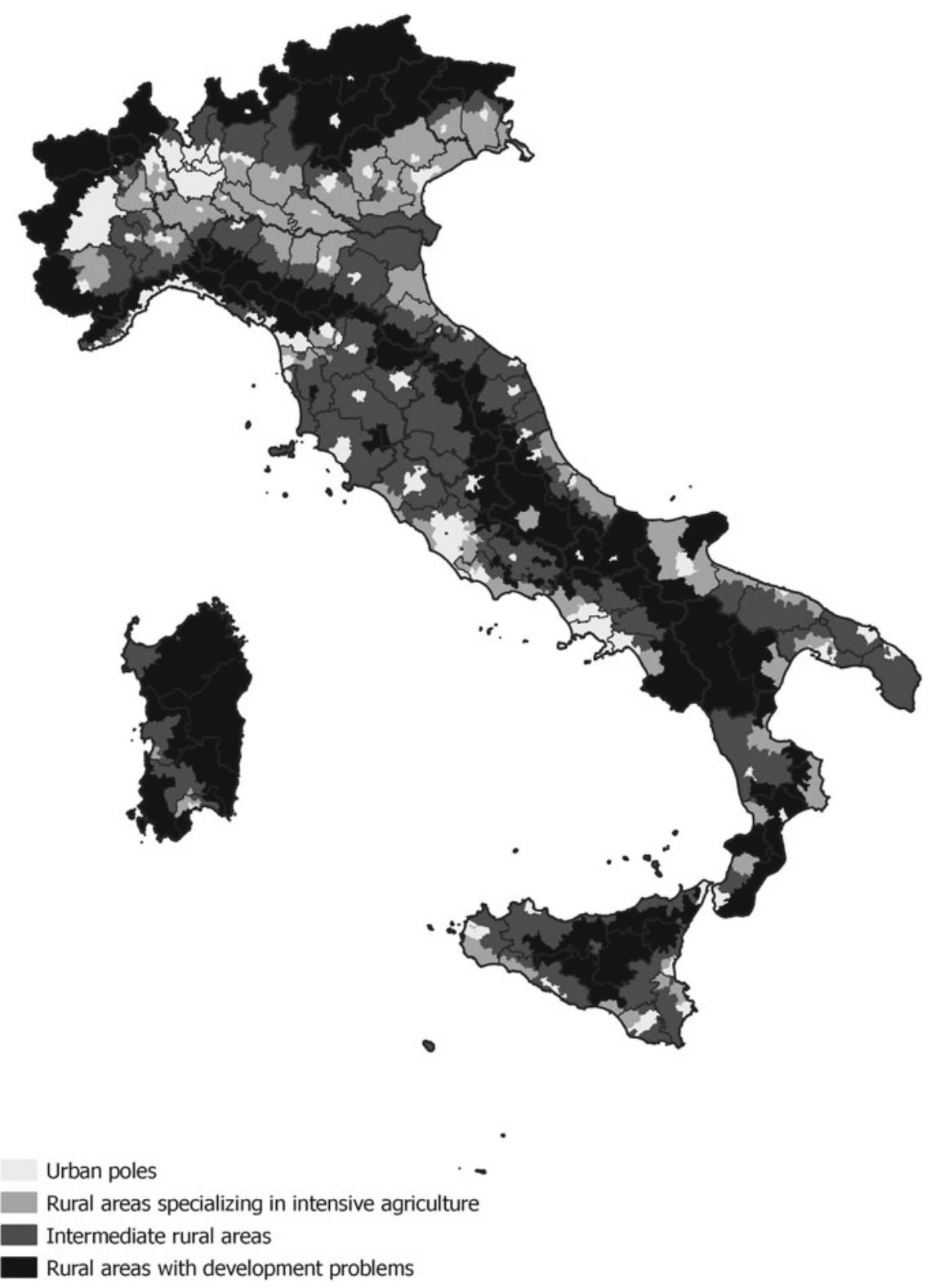

Fig. 2 A map of Italy according to the PSN 2007-2013 method. Source Italian Government (2007) 

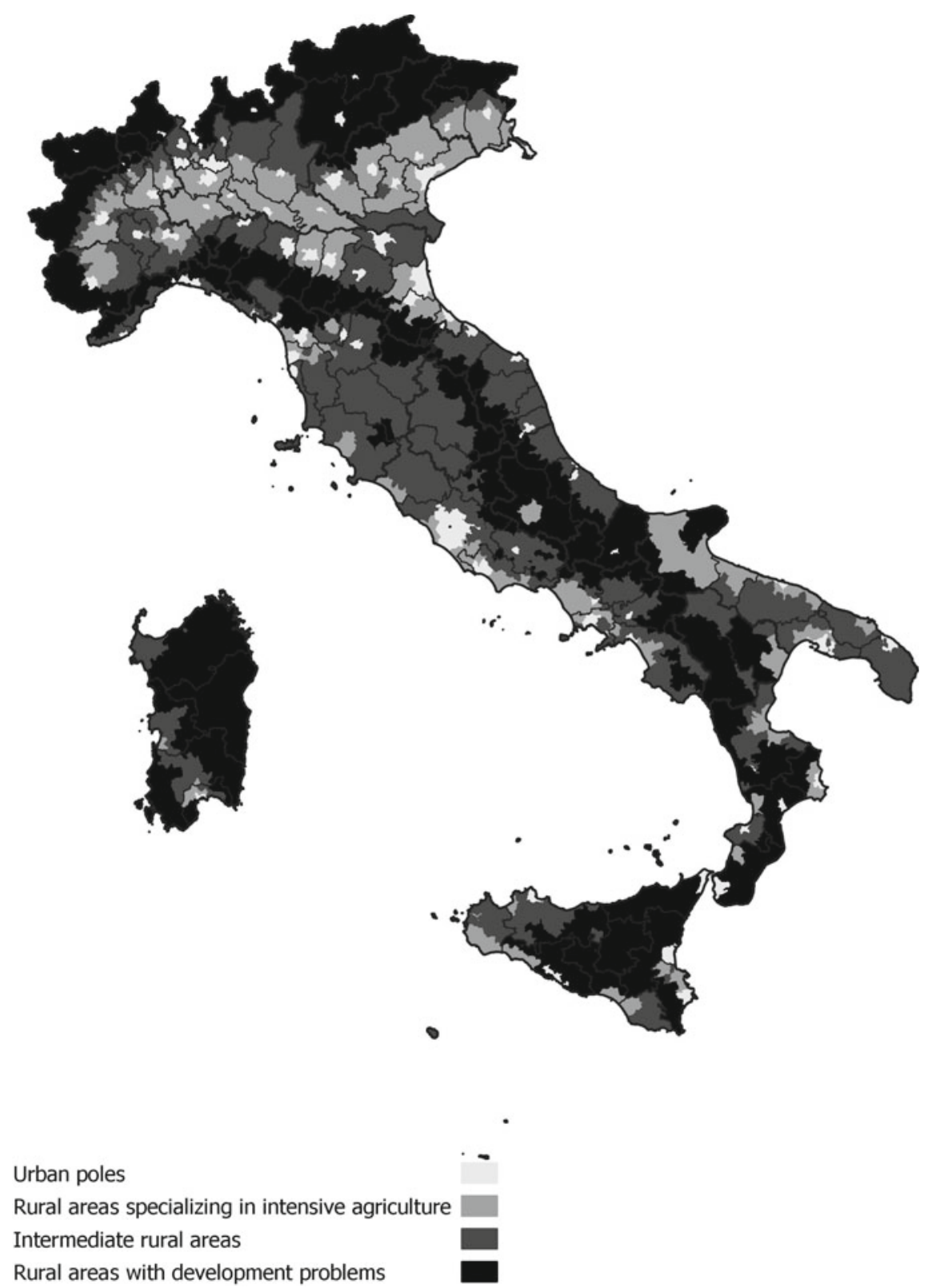

Fig. 3 A map of Italy according to the PSN 2014-2020 method. Source Italian Government (2014) 
- Ultra-remote areas-over 75 min away.

The last three categories constitute the inner areas and are mapped in Fig. 4.
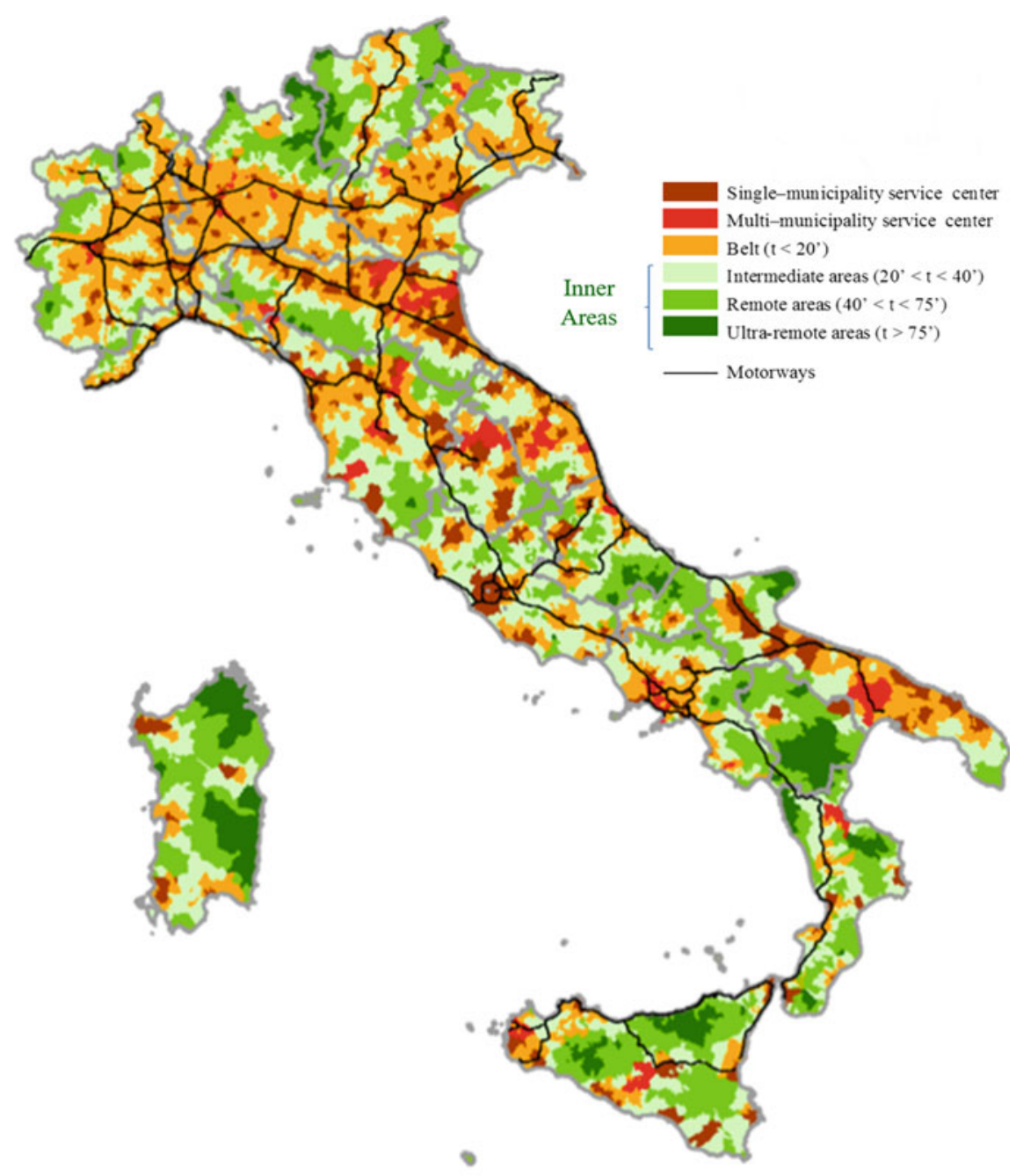

Fig. 4 A map of Italy according to the inner areas approach. Source Dipartimento per lo sviluppo e la coesione economica (2013) 
Most mountain areas are considered inner areas and, specifically, remote and ultra-remote areas. The Po valley is mapped more accurately than other territorial representations.

In 2014, the Ministry for Agricultural Policies, together with the National Rural Network, developed a method for defining rural territories, which would form the basis for defining the Leader strategy for start-up programming. This method does not consider the grid or the municipality as a reference statistical unit, instead considers the Gruppo di Azione Locale-Local action group GAL/LAG. LAGs are interinstitutional groups to which all the public and private actors in a group of contiguous municipalities belong. The method combines indicators concerning morphological, sociodemographic, and economic dimensions and clusters each municipality in the corresponding GAL/LAG. The morphological dimension is measured by some indicators related to the physical-territorial system, such as the municipal average size and the percentage of protected area in the total regional protected area. The sociodemographic dimension is defined by indicators related to the sociodemographic system, such as the average population size, the percentage of the population present in the total regional population, the aging index and the depopulation measure (1997-2007). The economic dimension is structured around some indicators like the employment in the most important economic sectors (agriculture, industry, and services ones), the dependency ration, the firms' average size, and the average size of a utilized agriculture area. Figure 5 here provides a more comprehensive graphic explanation of this method.

This method does not replace the territorial distinction applied in the 2010 National Atlas of Rural Territory, based on demographic dynamics and travel distances. Specifically, this distinction identifies two main categories (urban and rural areas) and other specific ones, such as metropolitan areas, important cities and local systems of cities with at least 250,000 inhabitants, other central municipalities, intermediate areas and internal and outermost areas. Compared to other methods, it very accurately details the territorial diversity of central Italy, as well as the urban structure and system of inner areas in the rest of the country. Figure 6 displays a graphical representation of this method.

\section{Discussion}

Urban-rural typologies represent an important means of categorization to methodologically support scholars to read territorial diversities and transformations and provide a framework for national and regional policymakers to target economic and social policies at a territorial level. Due to their importance, there have been many attempts in recent years to define them more accurately. This has also happened in Italy, where the highest number of methods have been developed in the 2005-2020 period. Here, however, research was fruitful in the earlier years of that period, while work in later years was limited to adapting or revising the methods tested in previous years. 


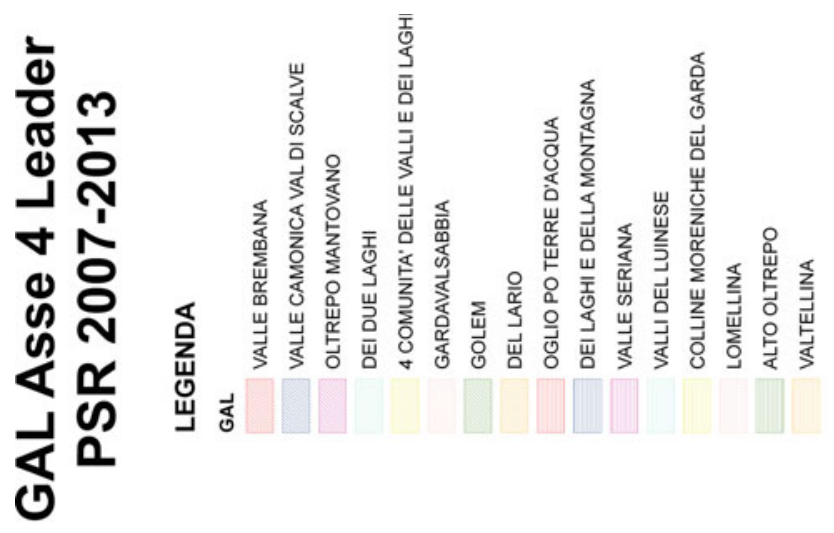

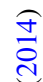

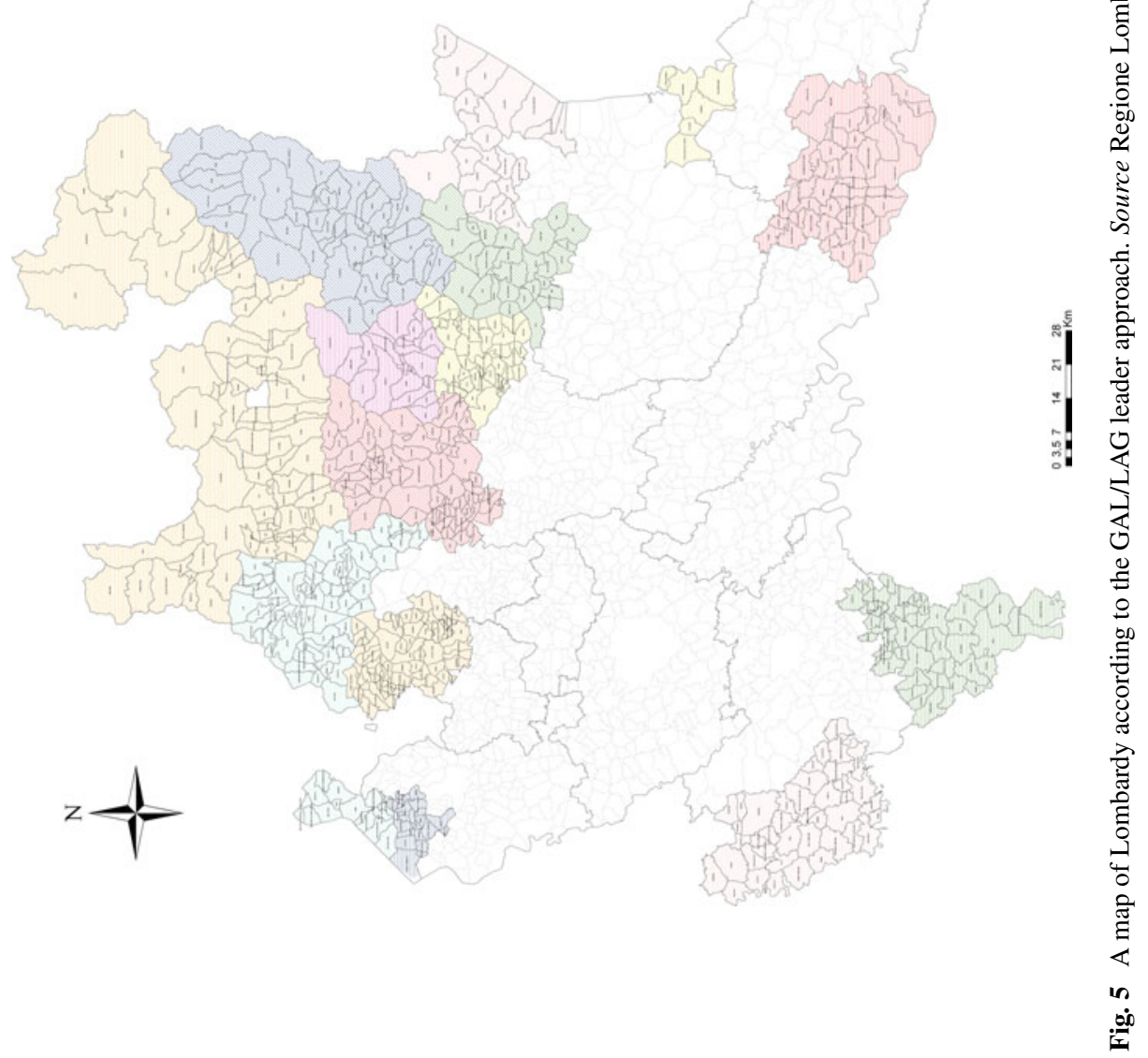




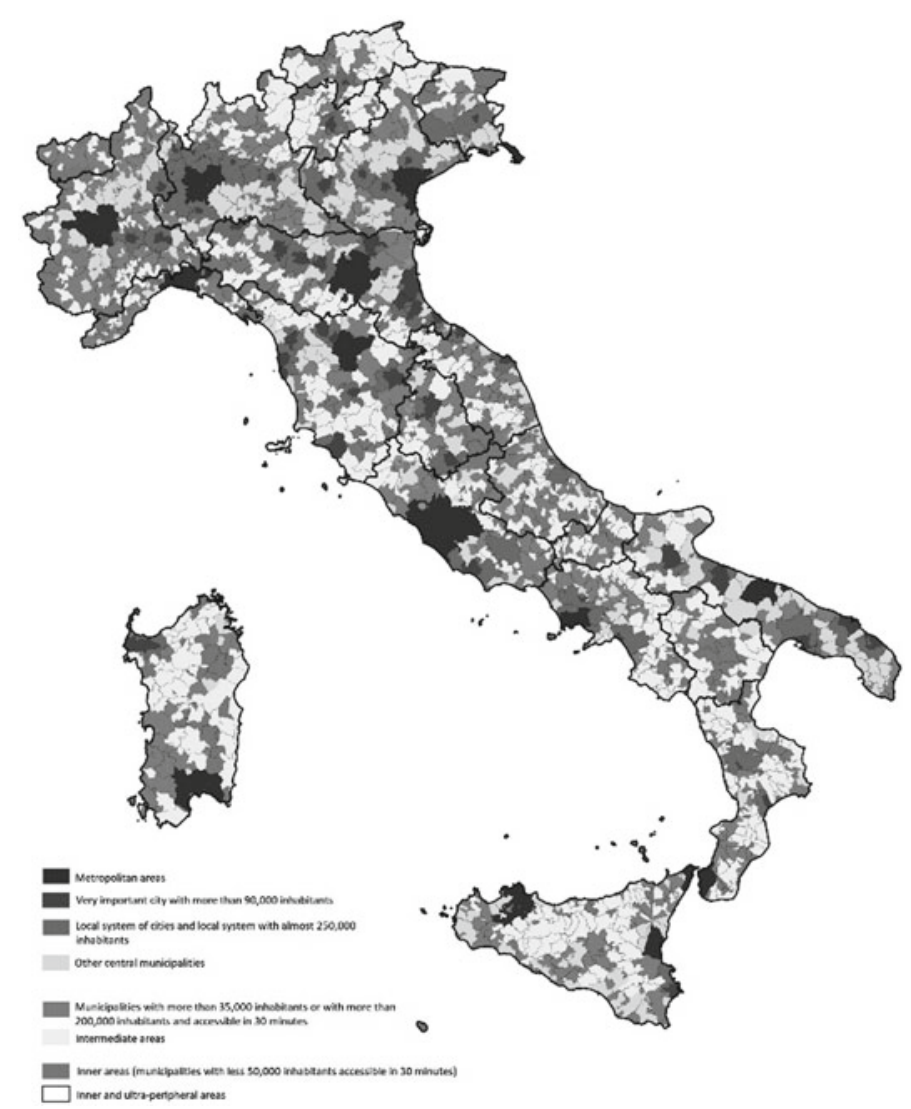

Fig. 6 A map of Italy according to Rete rurale nazionale. Source Rete rurale nazionale 2010

The obligation to adopt the OECD-EUROSTAT method to produce official statistics has certainly discouraged the development of new methods. In addition to being compulsory, this method is easily applicable across Europe and resolves distortions linked to the size of the various administrative units thanks to recent corrections. The method is, in fact, based on elementary statistical units (grid and municipalities) and map territories at the lowest possible territorial level, while only partially considering administrative boundaries (through the reaggregation of grids according to administrative boundaries). This approach reveals an aspiration to describe territories and their dynamics beyond their administrative boundaries. To this end, it abandons the traditional dichotomous categorization method of identifying just two categories of territories — urban and rural-and introduces a third category, which could be proxied to the intermediate territories or the continuum between urban and rural areas. The identification of these categories only involves applying demographic thresholds, while excluding other economic and morphological indicators. By only 
adopting three categories, the method offers a framework to produce uniform statistics and compare countries, but it is unable to accurately map territorial diversities. It is inspired by simplicity and comparable principles.

Although this method is mandatory, National Government Institutions have preferred to adopt specific and territorial-targeted methods to map their territories. The latter take a different perspective. While the statistical methods illustrated above are based on a dichotomous approach, the territorial-targeted methods are based on equality between territories or are built with the specific objective of mapping part of them and focusing mostly on rural (Ministry of Agriculture and National Rural Network) or inner areas (Strategy for Inner Areas). Consequently, instead of the traditional two, these methods identify four (PSN 1 and PSN 2), six (Inner Strategy), or eight (Atlas) territorial categories. Indeed, the specific distinction they adopt informs/influences policymakers' decisions as to which development policies to implement and how much funding to allocate to different territories. In this sense, territorial categorization is a prerequisite for proper decision-making as regards development policies and allocation of financial resources to territories lagging in terms of development. These methods offer more accurate territorial representations, above all concerning the mapping of the continuum, and use the municipality as a statistical unit of reference because more data are available at this territorial level. Only the Ministry of Agricultural Policy and the National Rural Network attempt to experiment with a new territorial unit, the LAG. This decision is motivated by the fact that rural policies, including European ones, are based on this unit. To offer accurate representations, these methods therefore employ a large variety of mainly economic, social, morphological, and accessibility indicators, and combines them with demographic ones. They then adopt more sophisticated statistical techniques, such as principal component analysis and multivariate analysis.

\section{Conclusion}

This paper offers an overview of the urban-rural methods formulated and implemented by statistical and governmental institutions over the last 15 years in Italy.

Some years ago, these actors began questioning the urban/rural dichotomy, proposing a multi-scalar approach and focusing on patterns of territorial continuity, thus challenging the framework based on traditional administrative boundaries. This led to an overproduction of classifications and definitions, which mapped the territories differently. Nevertheless, the OECD-EUROSTAT method remained the most widely used for official statistics and academic reports, and we are still far from the adoption of a single method of classification that describes all territorial diversities.

This has discouraged Italian scholars, who in recent years have stopped developing new methods. In order to relaunch the debate in light of the incessant periurbanization of the Italian territory, it is worth bearing in mind that each method 
offers a different territorial representation that depends, in turn, on the chosen statistical unit, the territorial categories defined and the methodology used. The choice of municipality or grid as statistical unit highlights a preference for simple, but accurate, representations, or the availability of data. Opting for others such as the LAGs reflects a desire not only to map the territories, but also to consider the economic relations between them. The definition of territorial categories is also crucial because the accuracy of the method depends on it. The adoption of a high number of categories is a sign of the capacity of the method to capture territorial diversity, while a low number indicates a desire to take a dichotomous approach. The choice of simple or complex statistical methods depends on the availability of variables and the degree of understanding of those who apply them.

Differences among methods depend on the combination of choices related to these three variables. It is not, however, possible to establish a priori which method is best or most representative of the territorial characteristics, but merely which is more in line with the objectives set by the experimenter.

When producing statistics or performing comparisons among territories, it is preferable to use a simple method, with few variables and territorial categories, as a basis. This is the case of ISTAT, which for these reasons favors the OECDEUROSTAT method based on population density and includes just three categories. If the objective is to capture territorial diversity or develop territorial-targeted policies, however, then more complex methods, such as those adopted by government institutions or scholars, are more effective.

Future studies should investigate the differences between the various representations and calculate how much of the Italian territory is mapped differently. They could also extend the use of the grid to more complex methods or experiments with new statistical units, by regrouping different grids and municipalities. Finally, they should more accurately map the differences among peri-urban territories.

\section{Appendix}

See Table 1. 


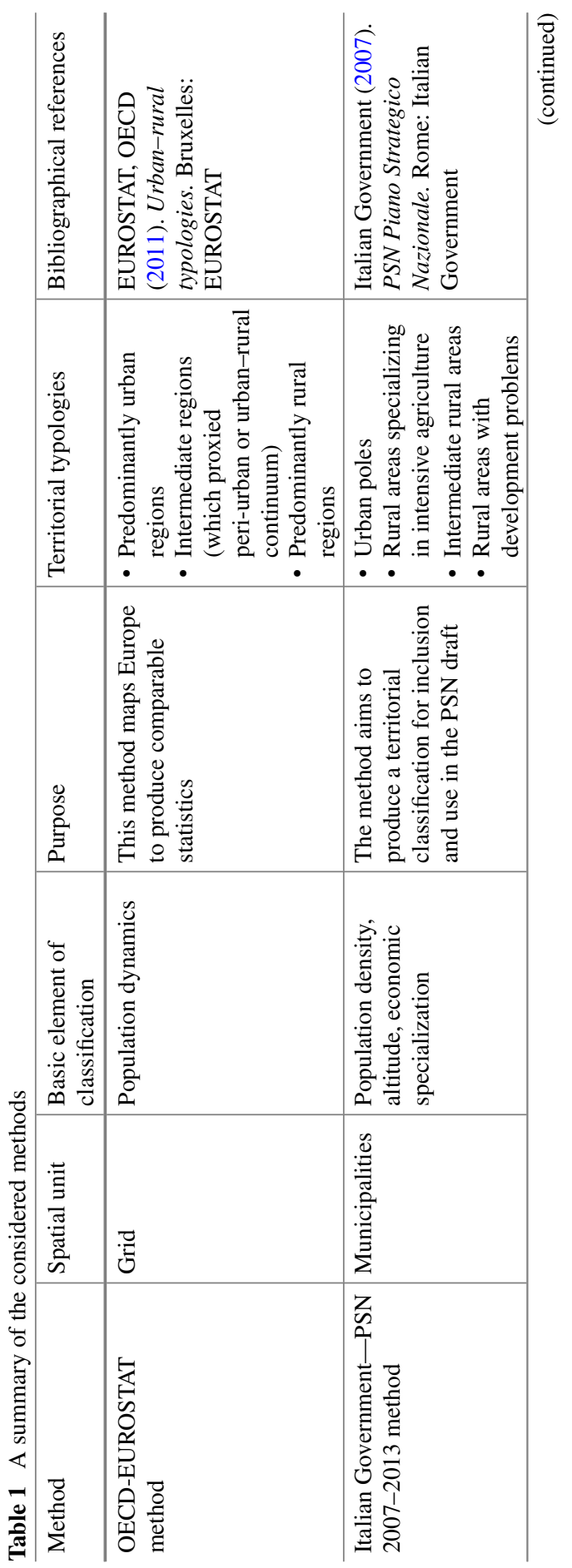




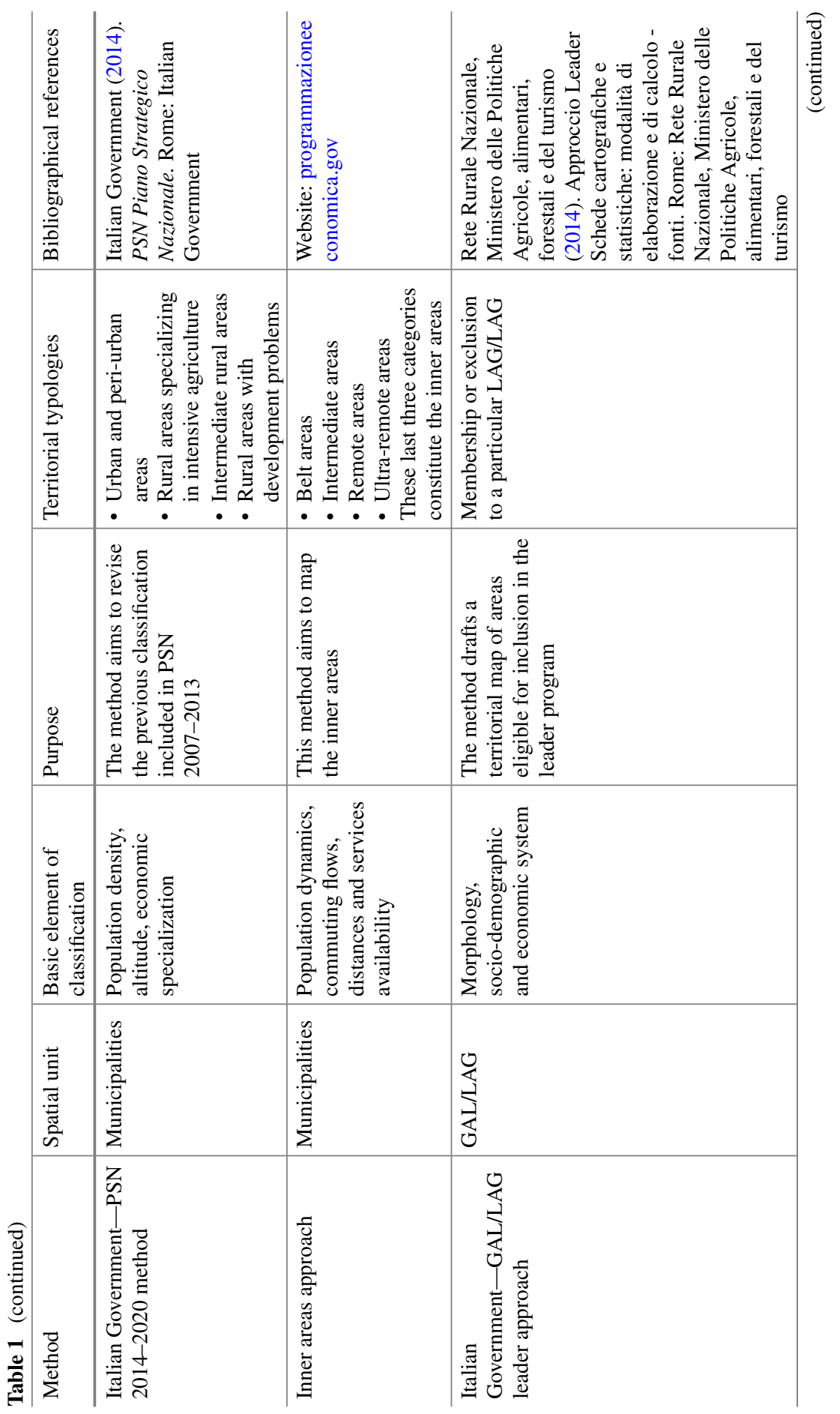




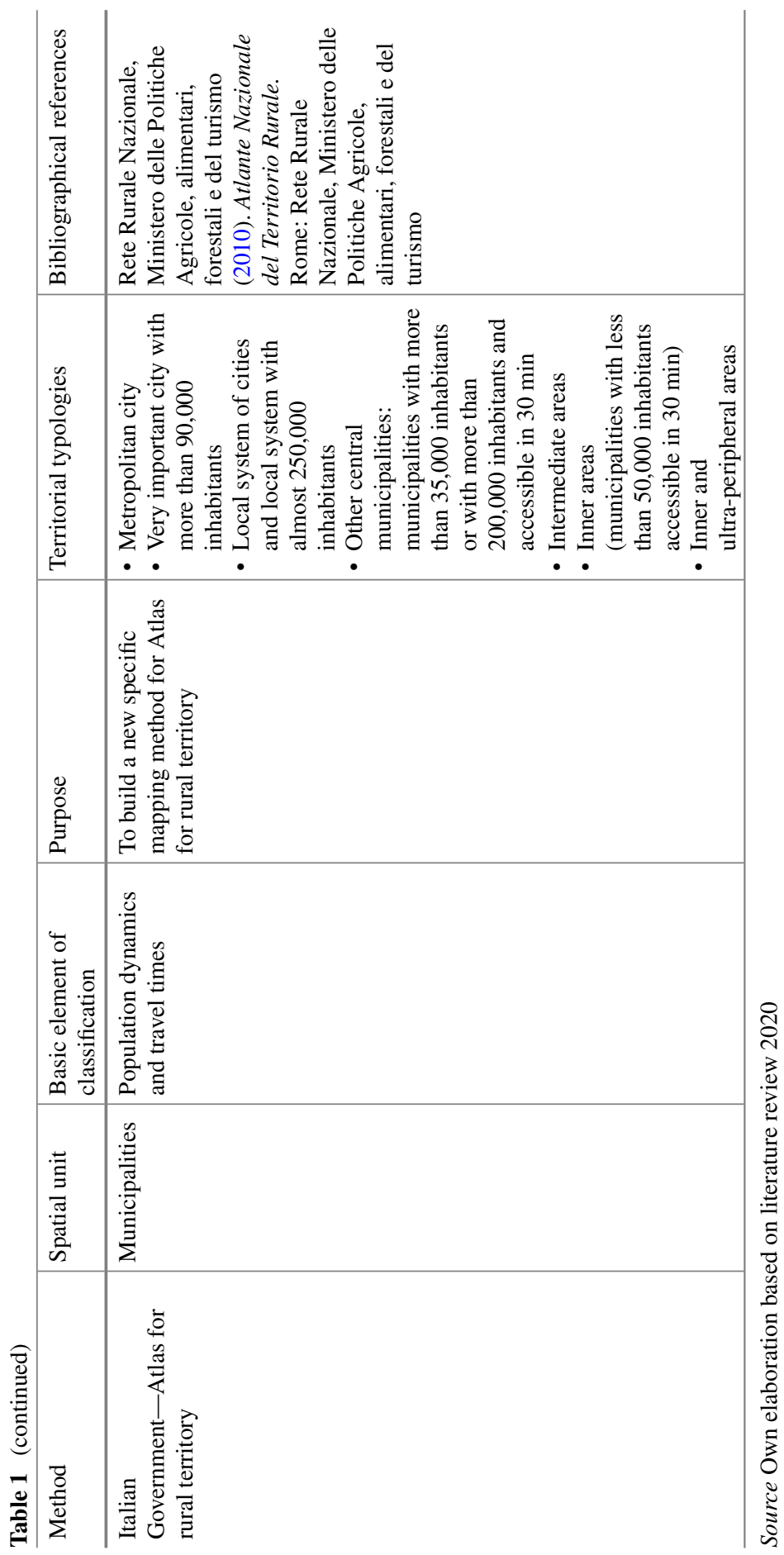




\section{References}

Accetturo A (2018) Urban development, agglomerations and aggregate growth in Italy. Spatial Productivity Lab, Trento

ANCI (2018) Dinamica demografica - dati. ANCI, Roma

Arellano B, Roca J (2017) Defining urban and rural areas: a new approach. In: Proceedings SPIE 10431, remote sensing technologies and applications in urban environments II, 104310E, 4 Oct 2017

Caracciolo A (2018) Some examples of analyzing the process of urbanization: Northern Italy (eighteenth to twentieth century). In: Schmal H (ed) Patterns of European urbanisation since 1500. Routledge, London, pp 133-141

Cattivelli V (2011) Teorie, metodi e strumenti per il governo delle relazioni urbano-rurali. Ph.D. thesis, Piacenza, Milano

Cattivelli V (2012) Né città né campagna, Per una lettura del territorio periurbano. MUP, Parma

Cattivelli V (2018) European urban-rural typologies: an overview. ERSA 2018, Cork

Cattivelli V, Iuzzolino G (2014) La rilevazione statistica delle agglomerazioni industriali: aspetti metodologici e un'applicazione ai dati censuari. AISRE, Conferenza di Scienze Regionali, Padova, $\mathrm{p}$ XXXV

Dadashpoor H, Somayeh A (2019) Land tenure-related conflicts in peri-urban areas: a review. Land Use Policy 85:218-229

Davoudi S, Stead D (2002) Urban-rural relationships: an introduction and a brief history. Built Environ 28(4):269-277

Dijkstra L, Poelman H (2017) Regional definition and classification. In: International encyclopedia of geography: people, the earth, environment and technology

Dipartimento per lo sviluppo e la coesione economica (2013) Strategia per le aree interne. Dipartimento per lo sviluppo e la coesione economica, Rome

Donadieu P (2012) Sciences du paysage. Entre theories et pratiques. Editions Lavoisier, Paris

Dymitrow M, Stenseke M (2016) Rural-urban blurring and the subjectivity within. Rural Landscapes Soc Environ Hist 3(1):4

ESPON (2018) ESPON bridges-balanced regional development in areas with geographical specificities. Final report. ESPON, Luxembourg

Esposito P, Patriarca F, Salvati L (2018) Tertiarization and land use change: the case of Italy. Econ Model 71:80-86

EUROSTAT (2010) Eurostat regional yearbook. EUROSTAT, Bruxelles

EUROSTAT (2017) EUROSTAT regional yearbook. EUROSTAT, Luxembourg

EUROSTAT (2018) Urban-rural typology. EUROSTAT, Bruxelles. https://ec.europa.eu/eurostat/sta tisticsexplained/index.php/Archive:Urban-rural_typology (last access, December 2019)

EUROSTAT, OECD (2011) Urban-rural typologies. EUROSTAT, Bruxelles

Hugo G (2017) New forms of urbanization: beyond the urban-rural dichotomy. Routledge, New York

ISTAT (2017) Forme, livelli e dinamiche della urbanizzazione in Italia. ISTAT, Rome

Italian Government (2007) PSN Piano Strategico Nazionale. Italian Government, Rome

Italian Government (2014) PSN Piano Strategico Nazionale. Italian Government, Rome

Mustafa A, Cools M, Saadi I, Teller J (2015) Urban development as a continuum: a multinomial logistic regression approach. In: Gervasi O et al (eds) Computational science and its applicationsICCSA 2015, ICCSA 2015, Lecture notes in computer science, vol 9157. Springer, Cham

Pagliacci F (2017) Measuring EU urban-rural continuum through fuzzy logic. Tijdschrift Voor Economische En Sociale Geografie 108(2):157-174

Regione Lombardia, Sostegno allo Sviluppo Locale Leader (2014) https://www.regione.lombardia. it/wps/portal/istituzionale/HP/DettaglioRedazionale/servizi-e-informazioni/enti-e-operatori/agr icoltura/programma-leader-e-gruppidi-azione-locale-gal/gal-psl-leader (last access, September 2020) 
Rete Rurale Nazionale, Ministero delle Politiche Agricole, alimentari, forestali e del turismo (2010) Atlante Nazionale del Territorio Rurale. Rete Rurale Nazionale, Ministero delle Politiche Agricole, alimentari, forestali e del turismo, Rome

Rete Rurale Nazionale, Ministero delle Politiche Agricole, alimentari, forestali e del turismo (2014) Approccio Leader Schede cartografiche e statistiche: modalita' di elaborazione e di calcolo - fonti. Rete Rurale Nazionale, Ministero delle Politiche Agricole, alimentari, forestali e del turismo, Rome

Romano B, Zullo F, Fiorini L, Marucci A, Ciabò S (2017) Land transformation of Italy due to half a century of urbanization. Land Use Policy 67:387-400

Simon D (2008) Urban environments: issues on the peri-urban fringe. Annu Rev Environ Resour 33

Simon D, McGregor D, Thompson D (2006) Contemporary perspectives on the periurban zones of cities in developing areas. In: The peri-urban interface: approaches to sustainable natural and human resource use, pp 1-17

Timberlake M (2017) The world-system perspective and urbanization. In: Xuefei Ren RK (ed) The globalizing cities reader. Routledge, London

Wandl A, Magoni M (2017) Sustainable planning of peri-urban areas: introduction to the special issue. Plann Pract Res 32(1):1-3

Wandl A, Nadin V, Zonneveld W, Rooij R (2014) Beyond urban-rural classifications: characterising and mapping territories in-between across Europe. Landscape Urban Plann 130:50-63

Open Access This chapter is licensed under the terms of the Creative Commons Attribution 4.0 International License (http://creativecommons.org/licenses/by/4.0/), which permits use, sharing, adaptation, distribution and reproduction in any medium or format, as long as you give appropriate credit to the original author(s) and the source, provide a link to the Creative Commons license and indicate if changes were made.

The images or other third party material in this chapter are included in the chapter's Creative Commons license, unless indicated otherwise in a credit line to the material. If material is not included in the chapter's Creative Commons license and your intended use is not permitted by statutory regulation or exceeds the permitted use, you will need to obtain permission directly from the copyright holder.

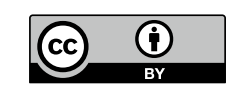

